\title{
A COMPLEXIDADE DO CONFLITO AMBIENTAL INTERNACIONAL E A MEDIAÇÃO DE CONFLITOS. A ATUAÇÃO DA UNIDADE DE APOIO À MEDIAÇÃO DA ONU.
}

Juliano Locatelli Santos ${ }^{1}$

\section{Resumo}

O presente estudo trata das características e peculiaridades do conflito ambiental, destacando os diversos aspectos que o permeiam e os interesses em disputa quando se trata de relações internacionais, ou ainda de conflitos internos no âmbito dos países. Através do relato de dois casos específicos em que melhor se podem captar algumas das características e vicissitudes típicas do conflito que envolve o meio ambiente, extraemse alguns dos aspectos mais presentes no conflito ambiental. Por fim, a partir das características apuradas nestes casos específicos, passa-se a tratar do modo como atualmente está constituída a Unidade de Apoio à Mediação das Nações Unidas, enquanto a experiência concreta melhor formulada a nível global para o tratamento do conflito ambiental e suas particularidades. Metodologicamente, o estudo se vale da pesquisa bibliográfica e documental dedutiva e do estudo de caso, concluindo pelo entendimento de que na atualidade as Nações Unidas contem com uma estrutura de múltipla abordagem, melhor apropriada para o tratamento dos conflitos ambientais regionais e transnacionais.

Palavras-chave: Mediação de conflitos. Dano ambiental. Conflito. Organização das Nações Unidas.

\begin{abstract}
The present study treats with the characteristics and peculiarities of the environmental conflict, highlighting the various aspects that permeate it and the interests in dispute when it comes to international relations, or even internal conflicts within the countries. Through the report of two specific cases in which one can better capture some of the characteristics and vicissitudes typical of the conflict involving the environment, some of the most present aspects of the environmental conflict are extracted. Lastly, based on the characteristics of these specific cases, the United Nations Mediation Support Unit is currently being set up, while the concrete experience better formulated at the global level for the treatment of the environmental conflict and its particularities. Methodologically, the study draws on the deductive bibliographic and documentary research and the case
\end{abstract}

${ }^{1}$ Mestrando em Direito (PUC-PR), área de concentração Direito Socioambiental e Sustentabilidade. Especialista em Direito Processual Civil (PUC-PR). Especialista em Direito Civil e Empresarial (PUC-PR). Graduado em Direito (PUCPR). Advogado. 
study, concluding that the United Nations currently has a multiple approach structure that is better suited to the treatment of regional and transnational environmental conflicts.

Keywords: Conflict mediation. Environmental damage. Conflict. United Nations.

\section{INTRODUÇÃO}

A perspectiva do desenvolvimento sustentável a partir do equilíbrio entre desenvolvimento econômico e meio ambiente, emerge em paralelo com o capitalismo global, na medida em que há uma nítida correlação entre a industrialização e a produção em massa decorrentes do aumento de mercados, e os danos advindos deste desenfreado processo produtivo. Mais matérias primas, mais mercados consumidores, mais lucro, trazem também mais danos ao meio ambiente. Compatibilizar um modelo de desenvolvimento econômico para além do mero padrão do produto interno bruto (NUSDEO, 2009, p. 149), tendo como norte e a minimização do dano ambiental, continua sendo um dos maiores desafios impostos à humanidade.

O intento deste estudo passa pela análise de formas mais eficientes de se pensar soluções para o conflito ambiental, perseguindo-se não apenas a compatibilização entre desenvolvimento econômico e proteção do meio ambiente, mas também contemplando a pacificação social. Inevitável considerar que a nível continental e global, começam a se estruturar sistemas que vem se reforçando no sentido de capacitarem-se para redimensionar as ameaças socioambientais visando a busca de soluções negociadas e que ao mesmo tempo possam se revelar duradouras. Neste sentido o presente estudo bibliográfico documental pretende seguir, valendo-se do método dedutivo e do estudo de casos, para em seguida analisar sobre o advento de uma estrutura a nível mundial que vem sendo edificada nos últimos anos para o enfrentamento dos 
conflitos ao redor do planeta, mas que longe da imposição de sanções, medidas agressivas ou interventivas, busca através do diálogo e da oportunização de escuta ativa aos envolvidos, o estabelecimento de canais pelos quais a pacificação seja viável.

\section{A DIMENSÃO DO CONFLITO AMBIENTAL INTERNACIONAL NA CONTEMPORANEIDADE}

O dano ambiental decorrente do capitalismo global não mais se circunscreve a antigas e convencionais delimitações dos Estados Nacionais, calcada nas tradicionais noções de soberania, povo e território. Ulrich Beck observa que é típica da sociedade de risco global um dano ambiental que transpassa fronteiras, nacionalidades, povos e territórios. O reconhecimento da incalculabilidade dos perigos produzidos pelo desenvolvimento tecnoindustrial tornam forçoso repensarmos os fundamentos do contrato social e revisarmos as convenções e princípios da racionalidade (BECK, 2002, p. 122). Trata-se de um dano que está disperso no tempo e no espaço, e cujo controle é extremamente mais dificultoso, na medida em que seus sistemas de segurança se revelam frágeis e inconsistentes.

Grandes desastres ambientais do passado ilustram bem esta característica do dano ambiental da contemporaneidade, no que se refere ao seu aspecto transfronteiriço. O vazamento de gases tóxicos em Bhopal, India, em 1984, o desastre nuclear em Chernobyl em 1986, ou ainda a poluição do ar devido à queima incessante de centenas de poços de petróleo no Kuwait em meio à guerra do Golfo, em 1991, são alguns dos exemplos mais notórios e marcantes de como o dano ambiental de grandes proporções se alastra e ultrapassa fronteiras. Ante a ineficácia dos sistemas internos de administração de justiça para disciplinar conflitos de maior magnitude, remanesce a alternativa de composição através de 
$101 \mid$ InterAção

novas sistemáticas de resolução destes conflitos, com a atuação de instâncias internacionais apropriadas para exercer com independência e imparcialidade a tarefa de dirimir o conflito e minimizar o dano, onde, de forma central ou periférica, o macroberm ambiental, enquanto objeto de uma titularidade ampla (LEITE, 2010, p. 166), esteja em risco.

O presente estudo pretende, após especificadas certas complexidades que permeiam o conflito ambiental, destacar a atuação e estruturação para a mediação de conflitos que vem sendo desenvolvida no âmbito das Nações Unidas, especialmente após a criação da Unidade de Apoio à Mediação (MSU), demonstrando que, apesar de tais dificuldades, o trabalho da ONU pode e deve servir de referência mundial, principalmente se passar a ser mais e melhor utilizado pelos organismos internacionais regionais.

\section{DOIS CASOS QUE PERMITEM COMPREENDER AS VICISSITUDES DO CONFLITO AMBIENTAL INTERNACIONAL E COMPLEXIDADE DA MEDIAÇÃO DE CONFLITOS}

Cumpre sinteticamente descrever dois casos que permitem retirar elementos relevantes para destacar algumas questões existentes no conflito ambiental, permitindo assim considerar algumas premissas.

Na região de Aceh, norte da Indonésia (UNITED NATIONS, 2008), o descobrimento de exploração de petróleo e gás natural pela multinacional Mobil, em 1971, trouxe além de danos ambientais consideráveis em extensas regiões territoriais, diversas outras animosidades étnicas, religiosas e políticas. Os postos de trabalho não foram ocupados pela população local, e sim por migrantes. Os recursos econômicos decorrentes não foram investidos na região, revertendo integralmente ao governo central em Jacarta. Para a região, ficava apenas a 
degradação ambiental. O descontentamento desencadeou um conflito armado que perdurou por muitos anos, e que convergiu em torno do pleito de independência da região de Aceh. Tentativas de mediação ao longo dos anos somente puderam ser retomadas após o grande tsunami que devastou a região em dezembro de 2004, causando centenas de milhares de mortes (CALVET, 2014). Foi a partir de quando um novo processo de mediação se iniciou, capitaneado pelo ex-Presidente da Finlândia, Martti Ahtissari, ganhador do Prêmio Nobel da Paz em 2008. Em 15 de agosto de 2005, foi assinado o Memorando de Compreensão, dirimindo grande parte do conflito, com melhor divisão dos recursos financeiros e ações voltadas para a minimização dos danos ambientais.

O outro caso, embora contenha uma tentativa de mediação infrutífera, merece menção, e refere-se a polêmica da instalação das indústrias de produção de pasta de celulose nas margens do Rio Uruguai, região fronteiriça entre Uruguai e Argentina, que foi celebrizado como a "guerra das papeleiras" (SMINK, 2010).

Na margem oriental do rio Uruguai, a partir de 2002, as empresas Ence e Botnia apresentaram projetos de parques industriais com o objetivo de explorar as áreas florestais ali existentes. A planta da Botnia se situaria ás margens do Rio Uruguai, próxima à ponte internacional Libertador San Martin, e à cidade uruguaia de Fray Bentos. O Estatuto do Rio Uruguai, de 1975, firmado entre os dois países, previa a comunicação prévia ao país vizinho no caso da instalação de empreendimentos que se valessem da exploração das águas do rio. Ante a insurgência argentina em relação ao empreendimento, o conflito se intensificou com a interdição, por grupos ambientalistas, da ponte internacional Libertador San Martin ao tráfego. As relações bilaterais entre os dois países se agravaram a ponto de serem formuladas denúncias recíprocas junto a Corte Internacional de Justiça e ao Mercosul. 
As esperanças na resolução negociada para a crise nas relações entre os dois países se renovaram com a proposta argentina, aceita pelo Uruguai, de realização de mediação pelo Rei da Espanha, Juan Carlos de Bordón (GALLAS, 2006). Todavia, as tratativas bilaterais com a facilitação da Casa Real espanhola se encerraram em 2007, sem êxito.

Decidiu-se a denúncia uruguaia no âmbito do Mercosul, apontando-se para a pertinência da alegação, imputando-se à Argentina a obrigação de desobstruir o acesso à Ponte Libertador San Martin. O que não contou com a boa vontade do Governo argentino, que por sua vez alegava não estar disposto a entrar em confronto com militantes ambientalistas. Já a Corte Internacional de Justiça enfim decide, em 20 de abril de 2010, que o Uruguai de fato teria descumprido as disposições do Estatuto do Rio Uruguai, referente a necessidade de informação prévia à Argentina. Entretanto, no que se refere a possíveis danos ambientais decorrentes de poluição do rio, a Corte Internacional de Justiça reconhece que não restou comprovada a contaminação conforme a alegação argentina (DIAZ, 2010).

Há portanto uma alteração no cenário do conflito, permeado pelas decisões das Cortes internacionais, apontando para a solidificação de um consenso técnico no sentido de que não se constatou a elevação da poluição do Rio Uruguai com a instalação da fábrica. Por fim, houve mudança das posturas dos governos, com a posse de Cristina Kirchner na Argentina em dezembro de 2007, e José Mujica no Uruguai em março de 2010. O que culmina com a assinatura de um acordo final em julho de 2010, cujo principal item é a priorização das normas já pautadas no Estatuto do Rio Uruguai de 1975, referentes ao monitoramento ambiental constante e conjunto do rio. 
104 InterAção

\section{ESPECIFICIDADES CARACTERÍSTICAS DO CONFLITO AMBIENTAL INTERNACIONAL}

Os dois casos relatados permitem algumas observações que auxiliam a compreensão sobre as diversas ramificações do conflito, demonstrando a complexidade do intrincado jogo de interesses e antagonismos que se colocam nas relações internacionais como pré-requisitos para uma mediação minimamente eficaz.

O conflito ambiental internacional quase nunca é um conflito apenas ambiental. Envolve diversas outras questões econômicas, divergências políticas, ou ainda rivalidades históricas, que podem passar também por antecedentes étnicos e até religiosos. O dano ambiental em muitas oportunidades, se insere como consequência, e não causa do conflito. Em geral o meio ambiente não tende em si a gerar um conflito, mas sim a exacerbá-lo a partir de sua interação com outros fatores ou causas estruturais (HERTZ; SIMAN; DRUMOND, 2016, p. 330). O que denota para se considere que se o dano ambiental internacional geralmente está associado a outras causas ou consequências de um conflito mais amplo, transversal, composto por dimensões sobrepostas. Compreender a existência desta complexidade é vital para que se compreenda também que as técnicas de mediação de conflitos nas relações internacionais, devem ser concebidas para se deparar com diversos vetores, um dos quais a questão ambiental. A resolução do conflito passa necessariamente por identificar-se os atores envolvidos e seus interesses em disputa. A identificação parcial tanto dos atores, quanto de seus interesses (VASCONCELOS, 2014, p. 22) tenderá a gerar soluções parciais, e que provavelmente comprometerão a finalidade facilitadora da mediação.

Ressalte-se que os dois casos antes narrados contaram com iniciativas de mediação intentadas por mediadores exógenos, externos, equidistantes do conflito. O mediador externo tem como principal vantagem a absoluta 
105 InterAção

imparcialidade em relação às partes. A atuação do mediador está diretamente ligada a um aspecto fundamental. Deve haver o consenso entre as partes sobre a sua independência. Trata-se de uma relação de isenção e confiança, que quando não pautada pela imparcialidade e pela equidistância (ALMEIDA; PAIVA, 2016, p. 108), macula por inteiro a mediação. No caso do conflito indonésio, provavelmente um mediador advindo da mesma região, poderia enfrentar uma série de questionamentos sobre suas relações ou predileções dentro do conflito. A atuação do Rei da Espanha, por sua vez, partia igualmente da premissa de que uma figura equidistante, embora com laços linguísticos e até culturais mais próximos, poderia se traduzir em uma atuação eficiente, o que não se concretizou do ponto de vista da efetividade de um acordo.

Mas a atuação de um mediador exógeno também tem suas potenciais desvantagens, quando este se ressente de um conhecimento maior acerca do conflito e suas particularidades. Um mediador regional, mais próximo do conflito, por vezes consegue captar e compreender com maior rapidez e naturalidade as várias dimensões e subdivisões deste conflito, o que pode ser essencial para uma atuação efetiva. A esse respeito, Elgström, Bercovich e Skau (2016, p. 288) manifestam sua posição em prol das vantagens da mediação endógena, quando destacam que a proximidade geográfica e a familiaridade com o conflito favorecem uma mediação mais eficaz. Os mesmos autores, entretanto, também destacam a parcialidade relacional como uma característica dos mediadores regionais que pertençam ao conflito, diante de seus possíveis laços de proximidade com alguma das partes (ELGSTRÖM; BERCOVICH; SKAU, 2016, p. 293).

Os exemplos mencionados permitem que se perceba que nem sempre a mediação ambiental internacional se dirige a um conflito entre unidades políticas soberanas. No caso indonésio, o conflito se dava entre o governo central e uma região específica, dentro do mesmo país. O que revela que também se encontram 
presentes assimetrias de poder entre as partes, uma dificuldade adicional para a mediação, na medida em que províncias tem sempre menor poder político, econômico, e muitas vezes até suporte jurídico para se insurgir contra um Estado soberano. Quando mesmo no âmbito interno, os sistemas de justiça destes Estados não conseguem equacionar um conflito tão ramificado e complexo, são as alternativas internacionais de resolução do conflito que se colocam à disposição. Quando esta supremacia de uma das partes se estende à mesa de negociação, por certo à atividade de mediação está devidamente disponível para manejar estes desequilíbrios (HIGHTON; ÁLVAREZ, 2013, p. 206), anular tais disparidades e promover a equivalência das oportunidades de escuta e de manifestação.

E por fim, outra particularidade que o exemplo sul-americano evidenciou, se refere a uma conexão muito próxima entre o discurso sobre o dano ambiental e a necessidade de sua comprovação técnica de forma evidente, através de laudos ou demais meios científicos. Não apenas para que se demonstre o dano em si, mas principalmente para que se consiga saber qual ou quais as origens do dano, no sentido de se evidenciar quais são os reais responsáveis pela degradação ambiental. Quando se trata de um dano localizado em regiões fronteiriças, maior a importância de se ter com clareza estas respostas, para que se possa construir soluções efetivas, e não calcadas em suposições ou construções hipotéticas não comprovadas faticamente.

Demonstrado onde se situa a mediação de conflitos ambientais internacionais, e a dimensão de suas complexidades, passamos a tratar do sistema específico mais concretamente preparado para o enfrentamento das diversas dificuldades mencionadas. $O$ fazemos referindo-nos à estrutura recentemente criada junto à ONU e voltada à mediação internacional de conflitos. 


\section{A ESTRUTURA E ATUAÇÃO DA UNIDADE DE APOIO À MEDIAÇÃO DA ONU}

Nas últimas décadas, percebe-se uma mudança no perfil da diplomacia internacional no âmbito da ONU, quando voltada para a resolução de conflitos entre Estados e dentro dos Estados. Passa-se a pensar uma articulação coexistente entre a diplomacia e um aporte técnico específico próprio da mediação de conflitos. Assim, assinalam Freitas e Cardoso (2015, p. 366) que se antes a mediação era realizada por representantes políticos e diplomatas, ao longo dos últimos vinte anos um número e variedade maior de atores estão inseridos nas atividades de mediação.

Em 1992, Institui-se o Departamento de Assuntos Políticos na ONU, e em 2004 (UNITED NATIONS, 2004) estabelece-se um consenso no sentido de que muito embora a demanda global em torno da mediação de conflitos tenha crescido, o investimento financeiro e de esforços organizativos do ponto de vista global não acompanhou este crescimento. Como consequência da consolidação deste entendimento, surge no âmbito da ONU em 2006 uma unidade destinada a prestar consultoria, apoio financeiro e logístico a esforços dialógicos de pacificação conduzidos ou apoiados pelas Nações Unidas. A Unidade de Apoio à Mediação, ou Mediation Support Unit, sigla MSU, passa a ser desde então cada vez melhor capacitada para atuar como um ente prestador de serviços (FREITAS; CARDOSO, 2015, p. 368), agregando qualificação técnica e estrutural de mesas de negociação em processos de paz pelo mundo, estendendo-se até mesmo no plano do auxílio a atividades já exercidas desde seu início por outras entidades e organizações.

Ao longo da última década, estruturou-se junto à MSU um importante repositório de vivências, experiências e relatos relativos aos processos de paz que constituem, juntamente com todo o aposte acadêmico e doutrinário trazidos 
pelas instituições universitárias e de pesquisa, um dos mais importantes polos de qualificação técnica para mediadores e estudiosos do tema.

Nesse sentido, em 2012 a MSU desenvolveu uma plataforma on line através da internet, de divulgação do seu banco de dados, estudos e relatórios, denominada peacemaker ${ }^{2}$. Ali estão contidas informações e notícias sobre o funcionamento da Unidade, a composição do quadro de mediadores, as atividades desenvolvidas, acordos de paz celebrados, diversos relatórios e documentos da ONU acerca da mediação de conflitos, e demais dados relevantes, na perspectiva de um trabalho voltado para a disseminação do conhecimento.

O suporte à mediação se desenvolve em determinadas vertentes. Uma das quais se refere ao apoio operacional direto a processos de paz, com a participação de equipes técnicas e a estruturação dos procedimentos negociais. Ainda, a MSU atua na formação de equipes de mediadores, não apenas no âmbito interno, mas sobretudo, disseminando e estruturando programas de treinamento e atualização.

A estruturação da MSU passa por uma engendrada rede participativa, que conta com um quadro fixo de mediadores, mas também se cerca de toda uma variedade de possibilidades de atuação conjunta. E para bem entender esta estruturação, torna-se oportuno destacar que dois modos de se desenvolver uma mediação podem ser descritos, do ponto de vista da figura do mediador. Primeiramente, são possíveis mediações onde o terceiro facilitador seja externo, exógeno. Da sua legítima presunção de imparcialidade, decorre um ganho no quesito da confiabilidade e isenção da figura do mediador externo. Por outro lado alguém que esteja melhor familiarizado com as características históricas, sociais, políticas e econômicas do conflito, pode em muitos casos melhor contribuir para a realização de uma intermediação mais humanizada e focada nas

2 Disponível em: https://peacemaker.un.org/ . Acessado em 18/12/2017. 
complexidades existentes. Nesse sentido, a participação conjunta de um mediador endógeno, ou mais próximo ao conflito, poderia trazer um maior contributo no sentido de melhor conectar-se aos discursos e aos problemas envolvidos.

Em relação a esta questão, a MSU encontrou alternativas e soluções. Primeiramente, compõe-se a MSU de uma equipe fixa e interna de mediadores sêniores, responsáveis por toda a organização e desenvolvimento técnico das práticas de gestão dos conflitos pela entidade. Há ainda uma equipe de espera de especialistas em mediação, a Standby Team of Mediation (SBT), criada em 2007 a partir de iniciativa e esforços do governo norueguês. Referida equipe, atualmente composta por oito membros fixos, tem como tarefa precípua melhorar a qualidade e a imediaticidade da oferta de apoio aos esforços de mediação, podendo se dirigir rapidamente a áreas de conflito.

Visando complementar o trabalho dos mediadores exógenos, e no intuito de melhor se aproximar da compreensão da natureza dos conflitos, instituiu-se um grupo de mediadores credenciados ao redor do mundo, os Mediator Roster, que pela sua maior proximidade, podem atender de modo mais capilar a imensa gama de conflitos, e também podem contribuir para uma visão mais regionalizada e específica.

Complementa esta estrutura o apoio de uma rede integrada composta por diversas entidades regionais e internacionais, além de Estados-membros e instituições, que em parceria e cooperação técnica com a ONU, desenvolvem atividades de aprimoramento teórico, treinamento e colaboração operacional. Nesse sentido, a Resolução 65/283 (UNITED NATIONS, 2011) da Assembleia Geral, a primeira resolução relativa à mediação de conflitos no âmbito da ONU, salienta a importância das parcerias e da cooperação internacional entre organizações regionais e sub-regionais e a ONU e a sociedade civil, no sentido de 
$110 \mid$ InterAção

complementar-se os esforços dos atores envolvidos. Soma-se ainda a esta estrutura, o trabalho do Grupo de Amigos da Mediação, composto por dezenas de Estados-membros, criado em 2010 pelos governos da Finlândia e da Turquia, e que tem como norte a divulgação e propagação das práticas da mediação pelo mundo, visando a inclusão do tema em acordos regionais internos e internacionais, bem como destacando a importância da participação da mulher e alertando para as possibilidades da mediação em face das disseminadas práticas de violência de gênero. Por fim, há ainda todo o aporte técnico do Conselho Consultivo Acadêmico da Mediação, criado em 2012, e que traz elevados patamares de qualificação de excelência decorrente do intercâmbio com instituições universitárias e de pesquisa.

Tem a MSU com uma estrutura organizada em rede, que dispõe de mediadores institucionalmente vinculados, mas que conta também com pesquisadores e quadros de renovado reconhecimento científico. Conta ainda com equipes de mediadores em sobreaviso para o atendimento de situações emergentes, e também com redes locais de profissionais que possam prestar contribuição a partir do conhecimento das regionalidades sempre presentes nos conflitos.

Atualmente, a MSU tem centrado seus esforços na abordagem de três vertentes consideradas chave no campo de atuação dos mediadores: o cessar fogo em processos de escalada da violência; a violência sexual realizada como forma de dominação e de torpe afirmação de supremacias étnicas e desconstrução de identidades, e instauradora de regimes de terror e migração de populações; recursos naturais, especialmente onde jazidas minerais, poluição ambiental, o acesso à água, a exploração predatória e a ocupação de territórios, entre outros temas, estejam presentes de modo central ou periférico em grande parte dos conflitos de dimensão internacional. 
$111 \mid$ InterAção

Estas vertentes demonstram que o conflito de âmbito internacional é composto de diversas ramificações e complexidades. A busca pelas razões pelas quais eclodem antagonismos não equacionados que se transformam em conflitos em maior escala, contém não raro diversas questões subjacentes, e que para o efetivo deslinde, ou quando muito para a retomada do diálogo, precisam ser enfrentadas. Em junho de 2012, o Relatório A/66/811 (UNITED NATIONS, 2012) da Assembleia Geral da ONU descrevia a então situação atual e os progressos e tendências em relação a mediação de conflitos. Nesta análise, já se detectava a complexidade da atividade de mediação, permeados por diversas questões ideológicas, políticas, étnicas e de baixa governança.

Ainda no âmbito das Nações Unidas, foram diversos os documentos advindos desde então, destacando-se em relação ao tema aqui tratado, a publicação "Natural Resources and conflict. A guyde for mediation practitioners." (UNITED NATIONS, 2015) Neste importante documento, um dos itens da respectiva conclusão aponta para a necessidade de obtenção de informações técnicas precisas sobre o recurso natural em questão, para que se possa concretamente permear o processo de mediação de elementos científicos a subsidiar os debates. Consta do referido dispositivo, como pré requisito a um processo eficiente de mediação, o acesso pleno a informações científicas e técnicas imparciais sobre o caso em disputa (ONU 2015).

\section{CONSIDERAÇÕES FINAIS}

Os objetivos do presente estudo se dirigiram precipuamente a demonstrar que o conflito onde o dano ambiental ocupa lugar central ou periférico, possui diversas vertentes, diversos atores e interesses dos mais variados. De modo que a disputa envolvendo o dano ambiental vem acompanhada de outros aspectos, 
112 InterAção

essencialmente ligados a fatores econômicos, socioculturais, étnicos, religiosos, entre outros. E a compreensão de que o conflito é permeado por esta diversidade de elementos sobrepostos é absolutamente importante para o seu enfrentamento sob a perspectiva para além da tradicional inflexão judicial de resolução de conflitos.

O conflito ambiental é um conflito complexo, justaposto por diversas questões nem sempre explícitas e visíveis. Para dirimi-lo, é igualmente necessário um aporte tecnicamente elaborado. Exsurgem assim as técnicas de mediação de conflitos como um instrumental absolutamente relevante no sentido de construir-se uma possibilidade concreta, efetiva, inclusiva, e acima de tudo reconhecedora das diversas posições e interesses em disputa, mas que aposta no diálogo, e não no confronto, para a superação de crises. A diagnose das diversas complexidades em torno do caso, a confiabilidade consensual na figura do mediador, a superação das assimetrias de poder, a utilização de recursos técnicos para a comprovação fática, são alguns dos desafios a uma mediação exitosa.

O que aponta para o conjunto de esforços e atuação em rede que recentemente vem sendo estruturados pela Organização das Nações Unidas, através da sua Unidade de Apoio à Mediação, que se estrutura ano a ano como uma das mais completas experiências de desenvolvimento da mediação para atuar diretamente em conflitos internacionais, sendo ou não o conflito ambiental a causa principal do conflito.

\section{REFERÊNCIAS}

ALMEIDA, Diogo A Rezende de; PAIVA, Fernanda. Princípios da mediação de conflitos. In: Mediação de conflitos: para iniciantes, praticantes e docentes. 
Almeida, Tania; Pelajo, Samantha; Jonathan, Eva (Coord). Salvador: Juspidivm, 2016.

BECK, Ulrich. La sociedad del riesgo global. España: Siglo Veinteuno, 2002.

CALVET, Jordi. A paz que veio com a destruição do tsunami em Aceh. UOL, São Paulo, 26/12/2014. Uol notícias. Disponível em:<https:/ / noticias.uol.com.br/ultimas-noticias/efe/2014/12/26/a-paz-queveio-com-a-destruicao-do-tsunami-em-aceh.htm>. Acessado em 02/12/2017.

DIAZ, Soledad Gallego. La Haya avala a Uruguay em la 'guerra de las papeleras'. El País. Buenos Aires, 20/04/2010. Internacional. Disponível em: https:/ / elpais.com/internacional/2010/04/20/actualidad/1271714413_850215. html. Acessado em 04/01/2018.

ELGSTRÖM, Ole; BERCOVICH, Jacob; SKAU, Carl. Organizações regionais e mediação internacional. A eficácia dos medidadores endógenos. In Mediação Internacional. HERZ, Monica; SIMAN, Maria; DRUMOND, Paula (Org.); Petrópolis, Rio de Janeiro: Vozes, Ed. PUC-Rio, 2016. P. 286/303.

FREITAS, Gilberto Passos de; CARDOSO, Simone Alves. Esforços institucionais da ONU no apoio à mediação de conflitos e paz inclusiva. In: I Encontro de Internacionalização do CONPEDI / organizadores: Samantha Ribeiro Meyer Pflug, Luiz Henrique Urquhart Cademartori. - Barcelona: Ediciones Laborum, 2015. Vol 3, p. 365-384. Disponível em: https://www.conpedi.org.br/wpcontent/uploads/2016/01/NOVO-Miolo-CONPEDI-vol.-3-em-moldesgr\%C3\%A1ficos-1.pdf. Acessado em: 17/12/2017.

GALLAS, Daniel. Argentina pede ajuda ao Rei da Espanha em crise com o Uruguai. BBC. Montevideo, 04/11/2006. BBC Brasil. Disponível em: http://www.bbc.com/portuguese/reporterbbc/story/2006/11/061104_urugu aidanielfn.shtml . Acessado em 10/01/2018.

HERZ, Monica; SIMAN, Maria; DRUMOND, Paula. Debates contemporâneos e tópicos especiais em mediação internacional. In Mediação Internacional. HERZ, Monica; SIMAN, Maria; DRUMOND, Paula (Org.); Petrópolis, Rio de Janeiro: Vozes, Ed. PUC-Rio, 2016.

HIGHTON, Elena I de Nolasco. Álvarez, Gladys. Mediación para resolver conflictos. $2^{\mathrm{a}}$ ed, $4^{\mathrm{a}}$ reimp. Buenos Aires: Ad-Hoc, 2013.

LEITE, José Rubens Morato. Sociedade de risco e Estado. In: CANOTILHO, José Joaquim Gomes; LEITE, José Rubens Morato (Org.). Direito constitucional ambiental brasileiro. 3. ed. rev. São Paulo: Saraiva, 2010. 
MEDEIROS, Marcelo de Almeida; SARAIVA, Mirian Gomes. Os atores subnacionais no mercosul: o caso das papeleiras. Revista Lua Nova, $n^{\circ} 78$, São Paulo, p. 77-108. 2009.

NUSDEO, Fábio. Capítulo IV. Sustentabilidade. In: Sustentabilidade e temas fundamentais de direito ambiental. MARQUES, José Roberto (org). Campinas: Millenium editora, 2009. p. 149.

SMINK, Veronica. Argentina y Uruguay celebran acuerdo final por papelera. BBC, Argentina, 16/11/2010. BBC Mundo. Disponível em: http://www.bbc.com/mundo/noticias/2010/11/101115_argentina_uruguay_ papelera_acuerdo_jg.shtml. Acessado em 04/01/2018.

UNITED NATIONS (ONU). Assembleia Geral. A/59/565. Report of the Highlevel Panel on Threats, Challenges and Change. A more security World: Our Shared Responsability, November 2004.

Conciliation Resources. Learning from the Indonesia-Aceh Peace process. Policy Bief. Accord, 2008. Disponível em: http:/ / www.cr.org/downloads/Accord\%2020_Indonesia_policybrief_2008_ENG_0.pdf. Acessado em 18/12/2017.

Assembleia Geral. A/65/283. Strengthening the role of mediation in the peaceful settlement of disputes, conflict prevention and resolution, july 2011. Disponível em:

https://peacemaker.un.org/sites/peacemaker.un.org/files/GARes_Strengthen ingTheRoleOfMediation_ARES65283\%28english\%29_1.pdf. Acessado em $18 / 12 / 2017$.

Secretaria Geral. A/66/811. Strengthening the role of mediation in the peaceful settlement of disputes, conflict prevention and resolution. Report of the Secretary-General, june 2012. Disponível em:

https://peacemaker.un.org/sites/peacemaker.un.org/files/SGReport_Strengh teningtheRoleofMediation_A66811.pdf. Acessado em 18/12/2017.

Natural Resources and conflict. A guyde for mediation practitioners.

Feb. 2015. Disponível em:

https:/ / peacemaker.un.org/sites/peacemaker.un.org/files/NRCMediation_U NDPAUNEP2015_0.pdf. Acessado em 18/12/2017

VASCONCELOS, Carlos Eduardo de. Mediação de conflitos e práticas restaurativas. $3^{\mathrm{a}}$ ed, São Paulo: Método, 2014. 